\title{
AESTHETICS AND MANAGEMENT: BRIDGING THE GAP
}

\author{
TERRY BROWN ${ }^{1}$, TIM KEANE ${ }^{2}$ and STEPHEN KAPLAN ${ }^{3}$ \\ ${ }^{1}$ Landscape Architecture and Regional Planning Program, School of Natural Resources, University of Michigan, MI (U.S.A.) \\ ${ }^{2}$ Department of Landscape Architecture, Kansas State University, KS (U.S.A.) \\ ${ }^{3}$ Department of Psychology, University of Michigan, MI (U.S.A.)
}

(Accepted for publication 29 November 1984)

\begin{abstract}
Brown, T., Keane, T. and Kaplan, S., 1986. Aesthetics and management: bridging the gap. Landscape Urban Plann., 13: 1-10.

It is possible to identify two relatively independent and distinct perspectives on what is valuable in the visual landscape. On the one hand there is the procedure for assessing visual quality which is utilized in one form or another by the various American land management agencies. An alternative approach is represented by the scholarly study of landscape aesthetics, a perspective which has its roots in the early 1700's in English literature, and has continued and evolved into its modern form. Inherent in this aesthetic study is the belief that the aesthetic qualities of landscapes are related to the informational and functional needs of humans. There is considerable value in using this traditional approach as a basis for improving current visual asessment processes. In order for this to occur, however, it must be possible to translate the rich information provided by the traditional approach into a mapped informational form that is compatible with the current visual assessment and management techniques. The effort to develop such a translation has focused on aspects of landform and land cover that might indicate the presence of such conceptual visual properties of the landscape as coherence, legibility and mystery. Initial steps to apply and test this translation have been taken, with promising results. The methodology used in these initial studies is relatively straightforward and widely applicable. Given the importance of the challenge and the encouragement of the preliminary results, it is hoped that others concerned with the fate of the landscape will be stimulated to apply these methods to their own landscape contexts.
\end{abstract}

\section{INTRODUCTION}

The study of landscape aesthetics has a long and rich history. Despite this long tradition, however, contemporary approaches to managing the landscape have taken little advantage of these insights. A major reason for the lack of compatibility between current work in landscape planning and management and the longer-standing traditional approaches stems from the demands of dealing with the large-scale environments that need to be considered in management decisions today. The long tradition of aesthetic analysis will remain of only scholarly interest unless two conditions are met. First, it must be possible to translate the fruits of such analysis into a form compatible with the systems currently used in making larger scale landscape decisions. In other words, information about aesthetics needs to be available in a mappable form. Second, it must be possible 
to demonstrate that such a translation merits the confidence of the landscape manager. Research findings, like those presented on this paper, constitute the beginning of such a demonstration. It is becoming increasingly clear that steps need to be taken to link the traditional approach to landscape aesthetics with assessment procedures in use today. Hopefully, others will become interested in joining this on-going effort.

\section{BACKGROUND}

Concern for the aesthetics of landscapes can be dated to the writings of Dennis and Shaftesbury at the start of the eighteenth century. Shaftesbury might well represent the beginning of this tradition in English thought, as he brought the concept of the sublime into the discussion of aesthetics. His work influenced the way in which his contemporaries and those who would follow him viewed the landscape around them.

\footnotetext{
"The wildness pleases. We seem to live alone with nature. We view her in her inmost recesses, and contemplate her with more delight in these original wilds than in the artificial labyrinths and feigned wildness of the palace." (Shaftesbury, 1709 , as quoted in Thacker, 1983.)
}

A second notable contributor was Hogarth, who added his ideas on beauty to the study of landscape aesthetics. Hogarth believed that aesthetic properties were intrinsic in certain line forms. It was Edmund Burke, however, who clarified the distinction between the beautiful and the sublime. Burke felt that the beautiful and the sublime could be explained in terms of what he referred to as "the passions". These passions were of two types: those of "self-preservation", giving rise to the sublime, and those of "society", which relate to beauty. The passions of self-preservation centered around pain or danger, which
Burke believed to be the most powerful of all passions.

"Whatever is fitted in any sort to excite the ideas of pain and danger, that is to say, whatever is in any sort terrible, or is conversant about terrible objects, or operates in a manner analogous to terror, is a source of the "sublime"; that is, it is productive of the strongest emotion which the mind is capable of feeling." (Boulton, 1958, as quoted in Appleton, 1975.)

Burke separated the passions of society into those which pertain to general society and those which pertain to generation (i.e. sexual passions); the latter, he felt, are especially important in forming the origin of our ideas of the beautiful.

It is striking to note the emphasis in Burke's analysis on survival factors as playing such a central role in the aesthetic. While there is obviously more to survival than dangers and procreation, the anchoring of aesthetic reactions in what we would now refer to as functional or evolutionary concerns is an intellectual achievement of the first order. It is only recently that the implications of this legacy are beginning to be spelled out.

The third in this triad of aesthetic concepts was introduced later in the 1700's by Gilpin. To the concepts of the beautiful and the sublime, he added the idea of the picturesque. Central here is the role of "roughness" or ruggedness. Hipple (1957) believes that "roughness affords greater variation... the taste for the picturesque is a taste for a greater measure of complexity and intricacy than either beautiful or sublime affords".

In characterizing these early perspectives, Hipple (1957) further points out that "All these aestheticians, whether philosophers, artists or amateurs, are concerned with the response of the mind to the qualities and relations of objects in nature and art". In 
other words, there was a deep and continuing interest in understanding why things in the world had such a strong impact on the mind. While the interpretations provided may seem from a modern perspective to be somewhat limited, and even distorted, it is striking how both survival themes (like danger) and informational themes (like complexity) dominate these discussions. There is an implicit sensitivity to what we would today call "informational needs". Central to these analyses was a concern for the practical and the functional in the patterns of information provided by nature.

This tradition of landscape aesthetics in this country continued into the nineteenth century, as is evidenced in the writing of A.J. Downing (particularly his Treatise on the Theory and Practice of Landscape Gardening, Adapted to North America, first published in 1841) (Foster, 1975). Even today, adaptations of these concepts continue to be central to the study of landscape.

Appleton, a geographer, offers a fascinating description of current approaches within the tradition of landscape aesthetics in his examination of "What is it we like about the landscape and why do we like it?" In his Experience of Landscape, Appleton (1975) expands upon the earlier work of Burke and Gilpin to develop the "prospect-refuge" theory. He proposes that aesthetic perception is related to the idea of safe habitat; one where it is possible to "see without being seen". Where these conditions are present, Appleton suggests that "perception is attended with pleasure; anxiety is set aside and relaxation is possible". The credibility of this theory is developed through a careful analysis of landscape paintings.

In a similar functionalist approach, environmental psychologists S. Kaplan and R. Kaplan have explored the role of order and interest in what makes a habitat safe. In their book
Cognition and Environment (1982), they speak of "human needs" in assessing environmental aesthetics:

"... as pervasive and far-reaching human needs, making sense and involvement, are important components in preference. These needs profoundly influence human preference for patterns of information... People prefer ... buth landscapes and books, interiors and organizations that offer promise of being involving and of making sense."

The approaches of both Appleton and of the Kaplans, in keeping with the earlier tradition, suggest a relationship between landscapes that are experienced as aesthetic and landscapes that provide a sense of security and health. However, these long-standing concerns of landscape aesthetics have had little impact on the way the American visual resource is assessed and managed.

\section{CURRENT VISUAL MANAGEMENT PRACTICES}

Although all federal land agencies in the United States have developed procedures for examining visual impacts, we will focus here on two similar and widely used approaches. Both the U.S. Forest Service Visual Management System (VMS), (USDA Forest Service, 1973, 1974) and the U.S. Bureau of Land Management Visual Resource Inventory and Evaluation System (VRIES) (USDI Bureau of Land Management, 1976) deal with natural-appearing landscapes characteristic of the western states. They classify landscapes on the basis of dominant landscape character types, and then attempt to delineate areas of varying scenic quality within each of these types. These classifications are based on land features, water features and vegetation. Further delineation within the dominant character types is based on a rating of variety for elements such as form, line, color and texture, as well as uniqueness and intrusion in the 
case of the VRIES. Sensitivity levels are then assigned based on the assumption that sensitivity is greater if more people see an area. By a process of combining the various assessments, the landscape units are then given certain management objectives and guidelines.

Both of these systems have made important contributions to the consideration and protection of scenic resources. At the same time, however, they both have serious shortcomings. The selection of what to evaluate and how to evaluate are based on professional judgment, making validity hard to assess. Indeed the validity of these assessment procedures can, and has been, questioned (e.g. Kaplan, R., 1979; Smardon, 1983; Miller, 1984).

Grden (1979) points out that "variety classes used in VMS would be appropriate if scenic quality were based only on the concept of variety". Variety, however, is not the only component of scenic quality, and in many instances may be only a small part of it (Wohlwill, 1976). Grden also notes that "the initial impression one gets from reading VMS and VRIES ... is that the Great Plains or Central Lowlands physiographic provinces of the United States would be entirely rated " $\mathrm{C}$ "--class scenery, and that need not be true". These and other flaws suggest that these systems have at best only limited applicability in the landscapes of urban, suburban and much of rural America. Furthermore, the systems are sometimes hard to interpret and implement, even by those trained to use them in the field (Grden, 1979).

In contrasting these two agency approaches with the traditional approach to landscape aesthetics, there are three key points to observe. (1) The agency approach seeks to determine scenic quality through the observation of certain artistic principles. The traditional approach seeks to determine scenic quality in terms of certain human needs which, on theoretical grounds, would be likely to play a role in what makes a landscape aesthetic (e.g. making sense, involvement, providing a safe and healthy environment). (2) The agency approach is based on professional judgment, whereas the traditional approach is based on a long history of human needs and human nature. (3) Many of the principles or assumptions underlying the agency approach have not been well tested to determine how accurately they predict what the public finds aesthetically pleasing. The traditional approach, especially in its modern version, has undergone initial testing of its validity in prediction of what the public finds pleasing and the results are quite promising (Kaplan, S., 1979b; Woodcock, 1982; Herzog, 1984; Kaplan, R., 1984).

From this comparison, it appears that the traditional approach can provide a sound foundation upon which to build an aesthetic assessment and management process. As mentioned earlier, however, the visual resource management procedures are applied to vast regions and must, therefore, rely heavily on landscape information that can be obtained from a map rather than from the site itself. Whether the kinds of concerns expressed by the traditional approach to landscape aesthetics are accessible from mapped information represents an interesting challenge. The next section describes work that begins to meet this challenge.

\section{BEGINNING THE TRANSLATION}

Brown and Itami (in Brown et al., 1979) proposed an approach that built upon both the traditional aspects of landscape aesthetics and upon map-based landscape information. The main objectives of their "Landscape Principles Study" were to assess the landscape character and to provide means for protection of the general landscape values of a rural region in Victoria, Australia.

To assess these values, the landscape was 
conceptualized as consisting of two interrelated systems; the natural (land-form) and the cultural (land-use) (after Research Planning and Design Associates, 1970). Together, these describe the physical components of the visual landscape. Selection of landscape dimensions within each of these two systems was based on the work of Anderson et al. (1976), with the land-form reflecting the permanent "immutable" components, while the cultural system is reflected by the landuse (land-cover) pattern.

The qualities which contribute to the scenic resource value of each of these systems were selected on the basis of the framework proposed by Kaplan and Wendt (1972). Kaplan, S. (1979a, in an update of the earlier version) discusses a series of qualities that relate to landscape aesthetics from a functional perspective. These are divided into the two main categories mentioned earlier of "making sense" and "involvement", reflecting the need both to comprehend the environment and to be engaged by it. Within each of these distinctions, the landscape is further examined in terms of both a "surface", or two-dimensional, space and the more inferential three-dimensional environment. Table I summarizes the four components that this framework entails.

TABLE I

Kaplan's (1979) theoretical model of landscape preference

\begin{tabular}{lll}
\hline & Making sense & Involvement \\
\hline The visual array & Coherence & Complexity \\
Three-dimensional space & Legibility & Mystery \\
\hline
\end{tabular}

Table II presents a summary of the Brown/ Itami framework, reflecting the landscape dimensions or features that were selected to represent the Kaplan theoretical model for each of the physical systems.

The qualities of the land-form that were thought to best characterize the "making sense" aspects were slope (defined as steepness of the land-form) and relative relief (defined as the change in elevation within the land-form unit). Both of these dimensions contribute to the legibility of the landscape.

TABLE II

Adapted from Brown/Itami (1979) model relating scenic resource values to landscape preference components

\begin{tabular}{lll}
\hline & Making sense & Involvement \\
\hline Land-form & $\begin{array}{l}\text { Slope } \\
\text { Relative relief }\end{array}$ & $\begin{array}{l}\text { Spatial diversity } \\
\text { Relief contrast }\end{array}$ \\
& $\begin{array}{ll}\text { Naturalism } \\
\text { Land-cover }\end{array}$ & Height contrast \\
& Compatibility & Internal variety \\
\hline
\end{tabular}

The two characteristics used to measure the "involvement" aspect of land-forms are both indicators of spatial definition; spatial diversity (defined as the variety or complexity of spaces created by the land-form) and relief contrast (defined as the difference in relief between adjacent land-form units). Spatial definition suggests enclosure of the landscape setting which helps to increase the inherent interest of the scene, thus increasing involvement. In addition, spatial definition as a function of the height of the surrounding land-form (relief contrast) suggests a sense of mystery as one is drawn into the scene to explore it further.

The two dimensions hypothesized to enhance the comprehension or "making sense" aspect of the land-cover system were naturalism (defined as the degree to which a landcover type is affected by man) and compatibility (defined by Hendrix and Fabos (1975) as the visual congruence of adjacent land-uses as a consequence of culturally acquired associations). Naturalism has been shown to be a strong predictor of preference (e.g. Anderson et al., 1976; Williamson and Chalmers, 1982). As Zube et al. (1974) observe, as the scene becomes more natural, land use tends to be 
more compatible. In relatively more urban settings, therefore, compatibility may provide a better measure of this element of the matrix.

Naturalism, it should be noted, is a variable that deserves a "handle with care" label. Kaplan and Wendt (1972) suggested that the naturalness of the setting influenced preference not through its effect on coherence, but through the special significance that nature content holds for people. Ratings of "naturalism" based on the appearance of slides (rather than based on map information, as was the case in the Brown/ltami study) can introduce another hazard. People seem to feel that nature is good; they thus tend to rate scenes they like as being more natural. Because of this potential confounding, very high correlations between a global, intuitive variable such as naturalism and preference leads one to suspect that naturalism has become a synonym for preference rather than a predictor of it.

The involvement aspects of land-cover were measured by both height contrast (the difference in average height of adjacent landuses) and internal variety (the differences in visual pattern within land-uses). Thus, for example, a forest adjacent to water would receive a high contrast rating, while open water adjacent to pasture would receive a low rating. While these reflect complexity between land-uses, the internal variety measure concerns complexity within a land-use or land-cover pattern.

These landscape dimensions formed the basis of a procedure for evaluating scenic resource value. Land-cover and land-form dimensions were assessed independently of each other before combining them to derive composite scenic resource values, and each of the dimensions was assessed from mapped information. After the separate assessments, the ratings were combined, yielding composite values which are then also represented as mapped information (Brown and Itami, 1982; for a more detailed description of this process see Brown et al., 1979).
This procedure for assessing scenic resource values, based on the described theoretical framework, has several advantages. It constitutes an attempt to recognize, identify and locate the differences in landscape character through an analysis of landscape features that are objectively derivable from map information alone. Implicit throughout the process is the understanding that these identifiable differences in landscape character may demand different management practices in order to protect that character from possible adverse effects of land-use changes.

\section{VALIDATION OF THE MODEL}

Although the Brown/Itami work yielded a methodology for assessing rural landscapes which led to mappable results, a question still remains as to whether the predicted values of scenic quality created by the procedure are congruent with preferences expressed by the public. In order to test this hypothesis, it is necessary to examine the relationship between the model-predicted values and preferences obtained from non-expert members of the public.

The purposes of such a validation are not only to test the model in the strict sense, but to guide necessary revisions. Preference testing is being proposed not as a substitute for scenic assessment, but as a tool for developing an improved scenic assessment procedure. Through a series of preference studies, a model can be developed and sharpened. Repeated applications in different contexts are required to fine-tune the model and to achieve a better understanding of the landscape dimensions that work best in different environmental contexts.

The preference framework suggested by the Kaplans' work has received numerous empirical tests, with these studies subsequently playing a role in guiding the development of the framework. Nonetheless, the Brown/Itami model breaks new ground. None of the previous empirical research gives a method by 
which map-readable aspects of the landscape correspond to such psychological variables as "making sense" and "involvement". Determining the adequacy of the Brown/Itami translation requires a new series of preferencebased studies.

Herbert (1981) provides an initial attempt at such validation. His study combined the approach suggested by the Brown/Itami framework with the methodology for assessing preferences that the Kaplans and their students have used extensively (Kaplan, S., 1979a; Kaplan, R., 1984). The purpose of the study was specifically to test the relationship between the Brown/Itami Landscape Principles Study and people's actual preference of scenes selected in terms of this framework.

The setting for this study also permitted replication of the Brown/Itami work, as the process was applied in a totally different environment. Oakland County, Michigan, was selected because of the large existing data base that was available in the form of a computer data bank consisting of 7600 four-ha cells. The computer program IMGRID (Sinton, 1977) was used for data manipulation in recreating the model

Oakland County is situated just north of metropolitan Detroit. The land-form is characteristic of much of the Great Lakes region of the United States in that it is a flat-torolling, glaciated landscape containing kettle and kame topography as well as ground and end moraines. This county possesses a large amount of dense tree cover, a large array of small inland lakes, and a number of state and regional recreation areas. Although the county has received a large influx of people from suburban Detroit, it has remained in primarily rural holdings, with extensive nonbuilt areas which maintain the county's overall rural character.

The procedure of assessing the land-form and land-cover aspects separately prior to developing composite scores was followed.
The composite map was divided into five equivalence classes, ranging from low visual resource value to very high visual resource value. The visual resource quality map generated by the IMGRID program provided a suitable number of areas in each visual resource value range from which to develop a photographic survey. The photographs, in turn, made it possible to test people's preferences and to compare them with the values predicted by the model.

Based on the areas identified on the map, 55 color slides were selected to represent each of the five equivalence classes. A total of 97 respondents (randomly selected from the introductory psychology subject pool) were asked to view this set of 55 slides. Their task was to indicate for each scene "the extent of your preference for the projected slide" using a 5-point rating scale (where $1=$ not at all and $5=$ very much).

To test the accuracy of the Brown/Itami model, a correlation coefficient was computed using the composite scenic value and the mean preference rating for each scene. The correlation obtained, 0.61 , is significant at $P<0.001$.

Another way to look at the relationship between the model and the rated preference involves an analysis that is not based on each of the scenes separately, but rather on the perceived groupings of the scenes. The preference methodology lends itself to a procedure that identifies meaningful groupings of scenes based on the preference ratings. This approach gives the researcher insight into the common patterns, or thematic clustering, of scenes based on the respondents' perceptions (Lingoes, 1972; Kaplan, R., 1975). Four well-defined groupings were obtained; these can be characterized as "predominantly vegetation" (consisting of "dense forest to partly open fields"), "pastoral" (including both open fields and panoramas), "residential" and "manicured" landscapes. The latter two were similar in being strongly human- 
influenced landscapes. Despite the human influence, however, the manicured landscapes had no visible dwellings; these scenes were, in fact, strikingly park-like and often included water. This grouping, not surprisingly, was the most preferred of the four.

Although there was no way of knowing in advance what these categories would be, it is possible to arrive at a meaningful predicted value for each category based on the model. This is achieved simply by averaging across the predicted values for the scenes in a category. In a similar fashion, mean preference ratings can be obtained for each of the categories. The relationship between these pairs of values is presented in Table III, which shows an identical ranking for the two procedures.

TABLE III

Relationship between expert-predicted and respondents" preference, from Herbert $(1981$, p. 75$)$. Both sets of means are based on a 5 -point scale; 5 = highest value

\begin{tabular}{llllll}
\hline Category & \multicolumn{2}{c}{ Predicted } & & \multicolumn{2}{c}{ Preference } \\
\cline { 2 - 3 } \cline { 6 - 6 } & Mean & Rank & & Mean & Rank \\
\hline Manicured landscapes & 4.16 & 1 & & 3.80 & 1 \\
Predominantly vegetation & 3.62 & 2 & & 3.50 & 2 \\
Pastoral & 2.91 & 3 & & 3.08 & 3 \\
Residential & 2.52 & 4 & & 2.81 & 4 \\
\hline
\end{tabular}

These results provide support and encouragement for further work of this kind. The tradition of aesthetic analysis does appear compatible with the requirements of managing large-scale environments. This initial study provides not only confirmation; it also provides focus and direction for further work in this area. One source of direction comes from the discrepancies between the predicted and actual values for a given group of scenes. Thus, for certain scenes where the preference values were higher than predicted, a common feature was the presence of smooth-textured grassy areas, suggesting that highly coherent land cover has a greater im- portance than that accorded to it by the model. Comparably, some scenes whose preference values were lower than predicted were relatively barren, suggesting the potentially powerful role of land-cover complexity. Ideally, both these variables would be better represented in future studies.

Herbert (1981) also points to mystery as another predictor variable that would ideally be incorporated in the methodology. Since mystery has been a powerful predictor in numerous studies, the potential usefulness of this addition is clear. On the other hand, the difficulty of extracting a highly abstract, cognitive variable of this kind from map information is formidable. Preliminary efforts in this direction by Itami and his students have achieved promising results (cf. Gimblett, 1984).

\section{CONCLUSIONS}

The material presented in this discussion is not intended to function merely as a report. It is also intended to serve as a sharing of a perspective and as an invitation. There is a way of looking at human reactions to landscape that is both humanistic and practical. The research potential of this perspective is vast and challenging. It is not yet known whether the same sorts of predictors apply to different landscapes and, if they do, whether their weightings differ in systematic and understandable fashion. Comparably, the methodology for translating map information to aesthetic concepts may also need to be matched to the particular kind of setting.

We hope researchers in this area will find this perspective challenging and fruitful. It is an adventure that is rich with potential for practical as well as intellectual benefits, and we particularly hope that environmental designers whose adherence to humanistic concerns had led them to doubt the usefulness of research will join in the exploration of these new possibilities. 


\section{ACKNOWLEDGEMENTS}

The authors would like to express their thanks to Professor Rachel Kaplan for her many contributions to this paper. The paper has also benefitted from the continuing dialogue of long standing with Professor Robert Itami. This research has been supported in part by the School of Natural Resources, University of Michigan, and by a grant from the National Endowment for the Arts.

\section{REFERENCES}

Anderson, T.W., Zube, E.H. and MacConnell, W.P., 1976. Predicting scenic resource values. In: E.H. Zube (Editor), Studies in Landscape Perception. Institute for Man and Environment, University of Massachusetts. pp. 6-79.

Appleton, J., 1975. The Experience of Landscape. Wiley, London, 293 pp.

Brown, T.J. and Itami, R.M., 1982. Landscape principles study: Procedures for assessment and. management Australia. Landscape J., 1: 113-121.

Brown, T.J., Itami, R.M. and King, R.W., 1979. Landscape Principles Study for Upper Yarra Valley and Dandenong Ranges. Vol. 2. Procedures for Landscape Assessment and Management. Centre for Environmental Studies, University of Melbourne, Australia, $162 \mathrm{pp}$.

Foster, E.H., 1975. The Civilized Wilderness: Background to American Romantic Literature, 1817-1860. Free Press, New York, $220 \mathrm{pp}$.

Gimblett, H.R., 1984. Mystery as a dimension of rural landscape preference. Master of Landscape Architecture Thesis, University of Guelph, $77 \mathrm{pp}$.

Grden, B.G., 1979. Evaluation and recommendations concerning the visual resource inventory and evaluation systems used within the Forest Service and the Bureau of Land Management. In: Proceedings of Our National Landscape. USDA Forest Service General Technical Report PSW-35, pp. 296-304.

Hendrix, W.G. and Fabos, J. Gy., 1975. Visual land use compatibility as a significant contributor to visual resource quality. Int. J. Environ. Stud., 8: 21-28.

Herbert, E.J., 1981. Visual resource analysis: Prediction and preference in Oakland County, Michigan. Master of Landscape Architecture Thesis, University of Michigan, $128 \mathrm{pp}$.

Herzog, T.R., 1984. A cognitive analysis of preference for field-and-forest environments. Landscape Res., 9: 10-16.

Hipple, W.J., 1957. The Beautiful, the Sublime, and the Picturesque in Eighteenth Century British Aesthetic Theory. University of Southern Illinois Press, Carbondale, IL, 390 pp.

Kaplan, R., 1975. Some methods and strategies in the prediction of preference. In: E.H. Zube, R.O. Brush and J. Gy.
Fabos (Editors), Landscape Assessment. Dowden, Hutchinson and Ross, Stroudsburg, PA, pp. 118-129.

Kaplan, R., 1979. Visual resources and the public: An empirical approach. In: Proceedings of Our National Landscape. USDA Forest Service General Technical Report PSW-35, pp. 209-216.

Kaplan, R., 1984. Assessing human concern for environmental decision-making. In: S.L. Hart and G.A. Enk (Editors), Improving Impact Assessment. Westview, Boulder, CO.

Kaplan, S., 1979a. Perception and landscape: Conceptions and misconceptions. In: Proceedings of Our National Landscape. USDA Forest Service General Technical Report PSW-35, pp. 241-248.

Kaplan, S., 1979b. Concerning the power of content-identifying methodologies. In: Assessing Amenity Resource Values. USDA Forest Service General Technical Report RM-68, pp. 4-13.

Kaplan, S. and Kaplan, R., 1982. Cognition and Environment: Functioning in an Uncertain World. Praeger, New York, $287 \mathrm{pp}$.

Kaplan, S. and Wendt, J.S., 1972. Preference and the visual environment: Complexity and some alternatives. In: W.J. Mitchell (Editor), Environmental Design: Research and Practice. Environmental Design Research Association, Washington, DC, pp. 6-8-1-6-8-5.

Lingoes, J.C., 1972. A general survey of the GuttmanLingoes nonmetric program series. In: R.H. Shepard, A.K. Romney and S.B. Nerlove (Editors), Multidimensional Scaling. Seminar, New York, pp. 52-68.

Miller, P.A., 1984. A comparative study of the BLM quality rating procedure and landscape preference dimensions. Landscape J., 3: 123-135.

Research Planning and Design Association, 1970. Appendix $\mathrm{N}$ : Visual and cultural environment. North Atlantic Regional Water Resources Study, U.S. Army Corps of Engineers, $127 \mathrm{pp}$.

Sinton, D.F., 1977. The user's guide to I.M.G.R.I.D. Harvard University, Department of Landscape Architecture, $124 \mathrm{pp}$.

Smardon, R.C. (Editor), 1983. The Future of Wetlands: Assessing Visual-Cultural Values. Allanheld and Osmun, Totowa, NJ, $226 \mathrm{pp}$.

Thacker, C., 1983. The Wildness Pleases: The Origins of Romanticism. St. Martin's Press, New York, 281 pp.

USDA Forest Service, 1973. National Forest Landscape Management, Vol. 1. Agricultural Handbook No. 434, Washington, DC, Government Printing Office, 76 pp.

USDA Forest Service, 1974. National Forest Landscape Management, Vol. 2. Agricultural Handbook No. 462, Washington, DC, Government Printing Office, $47 \mathrm{pp}$.

USDI Bureau of Land Management, 1976. Visual Resource Management. BLM Manual, Washington, DC, Government Printing Office, 38 pp.

Williamson, D.N. and Chalmers, J.A., 1982. Perception of forest scenic quality in northeastern Victoria: A technical report of research phases I and II. Landscape Management Series, Forest Commission Victoria, Melbourne, Australia, 229 pp. 
Wohlwill, J.F., 1976. Environmental aesthetics: The environment as a source of effect. In: I. Altman and J.F. Wohlwill (Editors), Human Behavior and Environment. Plenum, New York, pp. 37-86.

Woodcock, D.M., 1982. A functionalist approach to environmental preference. Doctoral Dissertation, University of Michigan, $352 \mathrm{pp}$.
Zube, E.H., Pitt, D.G. and Anderson, T.W., 1974. Perception and measurement of scenic resources in the southern Connecticut River valley. Publication No. 74-1, Institute for Man and Ilis Environment, University of Massachusetts, Amherst, MA, $191 \mathrm{pp}$. 